\title{
EXPLORANDO A AUSÊNCIA DA LINGUAGEM GRÁFICA VERBAL EM PROGRAMAS AUDIOVISUAIS EDUCATIVOS
}

\author{
FERNANDES, Rodrigo Queiroz Kühni \\ Mestrando; Universidade Federal de Pernambuco. \\ Rqk.fernandes@gmail.com \\ FERREIRA, Luiz Fernando Loureiro \\ Graduando; Universidade Federal de Pernambuco. \\ luizlflf@gmail.com \\ RODRIGUES, Diego \\ Graduando; Universidade Federal de Pernambuco. \\ Diegorodrigues.dr@gmail.com
}

Resumo: O presente estudo visa entender a necessidade da linguagem gráfica verbal em programas audiovisuais educativos, tomando como amostra para essa finalidade o Telecurso 2000, programa televisivo de repercussão nacional. Partindo de uma pesquisa pré-experimental, dois pequenos grupos de alunos de um colégio foram testados e enquanto foi exibida uma versão da vídeo-aula com textos presentes para o primeiro grupo, foi exibida essa mesma vídeo-aula com todos os textos removidos via edição de vídeo para o segundo grupo. O cruzamento dos dados obtidos nesse experimento levantou indícios relevantes para a importância da linguagem gráfica verbal no auxílio de programas audiovisuais educativos.

Palavras-chave: Design, informação, LGV, tipografia, audiovisual.

\begin{abstract}
This study aims to understand the necessity of verbal graphic language in educational programs, taking as a sample for this purpose the "Telecurso 2000" show, a television program with national impact. While performing a pre-experimental research, two small groups of students from the "Grande Passo" school were tested, with the first group being exposed to the original version of the video lesson, while the second one was being exposed to the same instructional video, but with removed texts via video editing. The crossing of the obtained data in this study raised important clues to the importance of verbal graphic language in the aid of audiovisual educational programs.
\end{abstract}

Keywords: Design, Information, VGL, typography, audiovisual. 


\section{INTRODUÇÃO}

A tipografia, linguagem gráfica verbal (LGV) ou o que poderíamos considerar como linguagem escrita, tem se mostrado muito presente na sociedade, sendo utilizada nas diversas mídias modernas como televisão, videojogos, websites ou redes sociais. Devido à sua forte presença, essa linguagem vem influenciando estudos, inicialmente mais relacionados com a linguística, mas que hoje a aproximam muito com questões do design gráfico ou, mais especificamente, do design da informação.

TWYMAN (1982) menciona que estamos nos aproximando de uma situação tal que qualquer pessoa alfabetizada terá quase tanto controle sobre o que é apresentado graficamente como sobre aquilo que é falado. Por isso mesmo, segundo ele, mais do que nunca é necessário estudarmos a linguagem gráfica, e particularmente a linguagem gráfica verbal.

No entanto, mesmo com o aumento da importância e dos estudos relacionados a essa linguagem, existe uma relação defendida por autores como DERRIDA (2004), que ao defender uma forma de logocentrismo afirma que a palavra falada seria considerada superior às outras formas de representação, inclusive a escrita. Ellen LUPTON (1999) sugere que essa tradição logocêntrica tem afetado consideravelmente a forma como o design como conhecimento e a contesta afirmando que, ao menos para o design, as questões de forma gráficas não podem ser preteridas ao suposto conteúdo verbal.

Independente da relação entre essas duas linguagens ser de subserviência ou não, podemos dizer que uma é fortemente relacionada com a outra, podendo, portanto, a LGV complementar ou auxiliar o significado da palavra falada durante a comunicação e vice versa. Essa questão leva-nos a considerar sobre o quanto, efetivamente, a LGV pode influenciar ou auxiliar na linguagem falada, principalmente em casos importantes como durante a transmissão de conhecimentos específicos.

Autores como SCHRIVER (1997) mencionam um papel retórico da tipografia de fornecer informações para facilitar o entendimento do leitor a respeito de um determinado documento tipográfico. Segundo ele, neste sentido a tipografia pode fornecer (a) informação 'sobre o argumento', delineando as características do texto que servem a propósitos particulares (fazendo com que um sumário, por exemplo, seja reconhecido como tal); (b) informação 'dentro do argumento', enfatizando partes do texto (por exemplo, o uso do itálico para destacar palavras e frases); (c) informação 'sobre suplementos ou adendos ao argumento' (como notas de rodapé, apêndices, etc.). Esse papel como foi citado, no entanto, parece estar muito ligado a documentos impressos como livros e revistas, levantando assim perguntas sobre a viabilidade dele ao se relacionar com outros elementos como a linguagem falada.

Com isso, surgiu a necessidade de buscar por uma mídia, entre as muitas modernas, aonde a LGV possuísse uma relação forte com a língua falada. Através dela evidenciou-se a área da educação, aonde existe essa relação bastante evidente em casos como quando o professor utiliza slides ou escreve palavras chaves no quadro como ferramentas para o auxilio da aula. Ainda dentro dessa área da educação, foi encontrada uma categoria de ensino aonde a influencia do design gráfico e da LGV era bastante pertinente durante a elaboração do conteúdo: a modalidade de ensino à distância através de vídeo-aulas, antes representada principalmente por clássicos nacionais como o Telecurso. 
Com o advento da internet permitindo o fácil acesso à obtenção, geração e transmissão de informação, a modalidade de ensino a distancia alcançou uma nova dimensão, sendo possível notar uma tendência crescente de vídeo-aulas ou tutoriais que abrangem os mais diversos tópicos em sites como o "youtube". Essa situação, na qual vemos os próprios usuários executarem todo o processo de elaboração das vídeoaulas sozinhos, nos remete à afirmação de TWYMAN (1982) sobre estarmos nos aproximando de uma situação aonde qualquer pessoa alfabetizada terá quase tanto controle sobre o que é apresentado graficamente como sobre aquilo que é falado. Portanto ela se mostra ideal para mensurar a importância da LGV no auxílio à transmissão de conhecimentos.

Dentro dessa área, foi escolhido o programa Telecurso 2000 como objeto de estudo por ser um programa nacional influente com um bom tempo de circulação e que, dentre os seus serviços oferecidos, possui vídeo-aulas para conteúdos escolares com qualidade reconhecível e com uma integração constante de textos durante a transmissão do seu conteúdo. Seguindo o principal questionamento sobre a influência da LGV durante a transmissão de conhecimentos foi elaborada uma pesquisa préexperimental aonde duas versões de uma mesma vídeo-aula escolhida seria exposta para grupos diferentes de alunos. A primeira versão sem quaisquer modificações, tal como foi elaborada por seus idealizadores, e a segunda com todos os textos ou intervenções da LGV excluídos para poder assim mensurar o seu impacto.

Durante a exibição dos vídeos, seria pedido também que os participantes de cada grupo realizassem anotações sobre os assuntos que acharem pertinente na aula e, ao término dessa exposição, eles deveriam realizar um teste para mensurar o quanto foi absorvido do conteúdo. Se espera através desse experimento compreender, pela comparação das anotações e respostas dos diferentes grupos, o quanto a LGV foi eficaz em direcionar a atenção de um usuário para o conhecimento abordado na aula. Acredita-se que o grupo exposto a vídeo-aula editada com todos os textos excluídos apresentará anotações mais desfocadas e que, embora ele possa captar a ideia e os assuntos gerais abordados, não conseguirá responder com tanta exatidão às perguntas mais objetivas.

\section{BREVE HISTÓRIA SOBRE O TELECURSO}

O Telecurso 2000, nosso objeto de estudo, se trata de um programa de Educação à distância aonde o aluno e o professor não precisam estar simultaneamente no mesmo espaço, cabendo ao aluno definir o ritmo dos seus estudos.

Apesar de popularizado nos últimos tempos, principalmente devido ao avanço da tecnologia que permitiu uma melhor interação à distancia entre educando e educador, essa modalidade de ensino já é um recurso utilizado há bastante tempo. No século XIX já haviam experiências bem sucedidas desse ensino na Europa através dos conhecidos cursos por correspondência e após a Primeira Guerra, a demanda social por educação aumentou ainda mais, surgindo com ela novas iniciativas para a educação. Impulsionadas também pelo avanço tecnológico da época, os serviços de correio e o uso do rádio se mostraram efetivos para essa modalidade de ensino.

Aqui no Brasil, a experiência da educação a distancia começou no final da década de 1930 com instituições que obtiveram resultados positivos como o Instituto Rádio Técnico Monitor e o Instituto Universal Brasileiro. Na década de 1990 surge o Telecurso 2000, voltado para a aceleração da educação com o fim de diminuir a 
defasagem escolar. Ele segue a Metodologia Telessala, onde os alunos assistem a teleaulas juntos com um professor formado no método.

Com o programa de ensino não se baseando apenas nas Teleaulas, tanto os vídeos quanto as apostilas e o professor em sala servem como uma parte dos recursos usados para o aprendizado, no entanto, esses vídeos, por serem exibidos constantemente na TV aberta brasileira e por possuírem uma linguagem simples, foram bem mais acessíveis para o aluno interessado em aprender.

Parte notável da linguagem utilizada pelo programa é justamente a presença do texto que, durante o programa, ajuda a marcar tópicos e a pontuar informações sobre o assunto tratado. O uso da LGV, então, se mostra presente em vários momentos distintos e breves, com pequenas porções de informação, sempre reforçando e destacando o assunto comentado pelos apresentadores e atores no momento. Esse destaque é dado de forma estratégica para salientar as informações mais relevantes do vídeo, pontuando o assunto proposto na aula. Em outras palavras, temos um recurso que guia o aluno / expectador a focar sua atenção à informação pertinente, dando pequenas dicas daquilo que já está sendo dito oralmente.

\section{METODOLOGIA DA PESQUISA}

Para a realização desse experimento, foi realizada uma pesquisa de campo com alunos do $2^{\circ}$ ano do ensino médio do colégio Grande Passo. Essa escola se destacou de outras por possuir uma coordenação prontificada, infraestrutura mais organizada e, acima de tudo, alunos dispostos a se voluntariarem. Mesmo assim, dificuldades foram encontradas ao programar uma data para a visita.

Durante a realização do experimento seria apresentada para um grupo de alunos (Grupo A), uma aula do Telecurso 2000, com textos presentes, e para outro grupo (Grupo B), seria apresentada a mesma vídeo-aula, dessa vez com todos os textos retirados através de softwares de edição de vídeos. Como podemos ver na figura I, a imagem da esquerda representa a vídeo-aula original, destinada para o grupo $A$, com os textos presentes, enquanto a da direita representa a vídeo-aula editada, destinada para o grupo $B$, com os textos removidos.

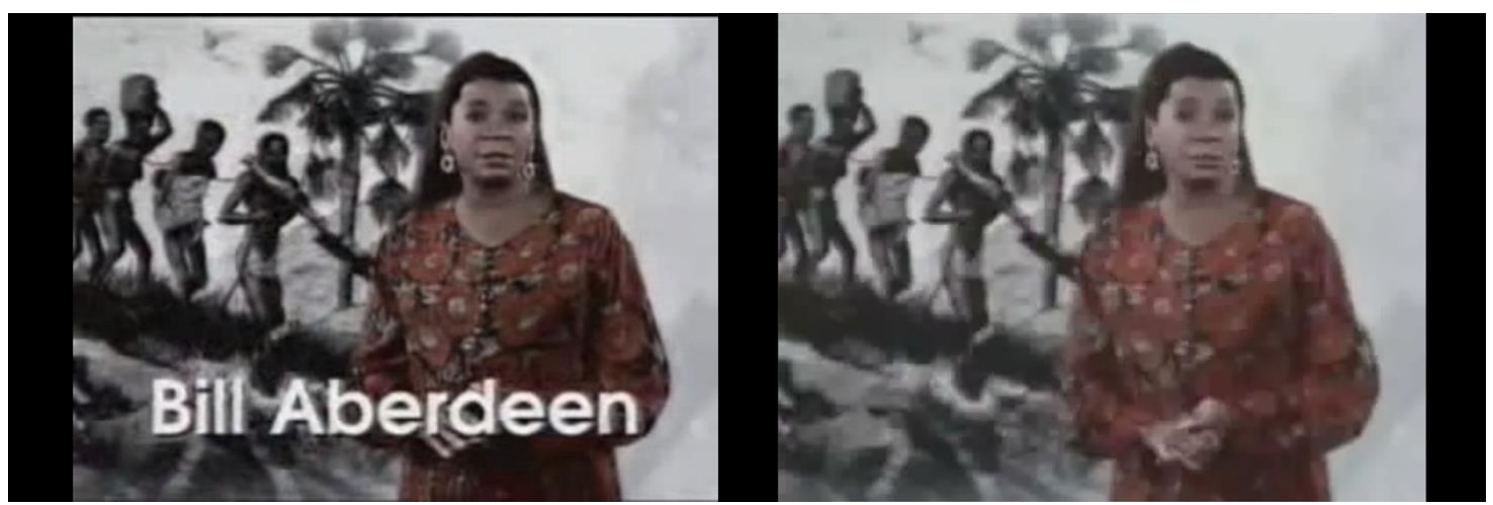

Figura 1: Versão não editada e editada da vídeo-aula escolhida.

Fonte: Telecurso 2000

Durante a exibição do vídeo, seria pedido que os alunos de ambos os grupos anotassem em uma folha de papel todas as informações que julgassem relevantes, como se estivessem assistindo a uma aula comum, e no término do vídeo, os dois grupos teriam que responder a um mesmo questionário com perguntas referentes aos 
assuntos abordados no vídeo. Todas as anotações e respostas do questionário de cada grupo foram recolhidas, para logo após, serem cruzadas e comparadas. A amostragem inicial contava com 15 alunos para cada grupo, no entanto houve problemas de comprometimento e estruturação durante a realização do experimento, que reduziram a amostragem drasticamente para oito alunos no grupo $A$ e seis alunos no Grupo

A decisão de realizar um questionário e de utilizar uma folha de anotações como meio de coletar as informações foi realizada para solucionar o problema de tempo e disponibilidade da escola aonde foi realizada a pesquisa, já que um debate com os alunos, como seria típico de um Focus Group, poderia se prolongar sem uma estimativa de término. Essa opção de coleta mostrou ser muito eficiente por ser uma forma de obter o registro direto do aluno, sem que ele sofresse qualquer influência do realizador do teste.

Foi escolhida a matéria de história para a vídeo-aula de exibição, por ser um campo que possibilita muitas anotações e alguma independência de conhecimento prévio para a absorção dos assuntos. Matérias humanas como geografia e história se mostravam mais eficientes para os objetivos da pesquisa do que matérias exatas como matemática ou física. Também foi preferível exercer a pesquisa com alunos de ensino médio, pois a maturidade para colaborar e o nível de conhecimentos acumulados poderiam ajudar na eficiência dos dados. As aulas do Telecurso 2000 são divididas em assuntos por nível de ensino e assim seria selecionado um vídeo com linguagem e conteúdo específico para esse público. Sob esses parâmetros, o assunto escolhido foi: a Lei Eusébio de Queiroz e os acontecimentos que marcaram o fim da escravidão no Brasil.

As perguntas elaboradas para o questionário foram todas abertas e direcionadas ao conteúdo da vídeo-aula. Dessa forma, poderíamos comparar o grau de influência dos textos em cada grupo através da absorção do assunto. No questionário havia perguntas gerais, aonde os alunos iriam discorrer de forma mais prolongada ao abordar várias partes do vídeo, e perguntas objetivas que eram satisfeitas com resposta curtas e específicas, como datas ou nomes de leis. Dessa forma, as respostas dadas poderiam ser medidas de forma diferente, com as perguntas objetivas podendo ser consideradas como um pouco mais difícil para a proposta, exigindo certo grau de atenção ao vídeo.

Como podemos ver no quadro I, as perguntas gerais são as de número 1, 3, 6 e 7, enquanto as perguntas objetivas são as de número 2, 4, 5 e 8 . Também foram elaboradas respostas para serem comparadas com as dos alunos à fim de classificá-las como satisfatórias, insatisfatórias ou parcialmente satisfatórias, com essa ultima contando como metade do valor pontuado de uma resposta satisfatória. Ambos os tipos de perguntas, gerais e objetivas, foram definidos através das informações pontuadas pela LGV no vídeo. Assim poderíamos descobrir se a absorção dessa informação estaria ligada ou não à presença dela.

Quadro I - Perguntas e respostas elaboradas a partir da vídeo-aula 


\begin{tabular}{|c|c|c|}
\hline 1 & $\begin{array}{l}\text { Por que era interessante } \\
\text { para Inglaterra acabar } \\
\text { com o tráfico negreiro? }\end{array}$ & $\begin{array}{l}\text { Acabar com o tráfico era uma maneira de tornar inviável a } \\
\text { escravidão, que já não se adequava ao novo modelo econômico do } \\
\text { trabalho livre, que se instalava com a Revolução industrial. }\end{array}$ \\
\hline 2 & $\begin{array}{l}\text { Cite um dos princípios do } \\
\text { liberalismo econômico inglês }\end{array}$ & "Trabalho livre" ou "livre comercio". \\
\hline 3 & $\begin{array}{l}\text { Por que o Brasil também } \\
\text { aderiu o fim do tráfico de } \\
\text { escravos? }\end{array}$ & $\begin{array}{l}\text { O Brasil sofria pressões externas e internas. A Inglaterra decretava } \\
\text { leis de fim ao tráfico e chegava até a boicotar os navios destinados } \\
\text { ao Brasil. O Brasil não podia confrontar a Inglaterra por depender } \\
\text { de seus empréstimos e por ela controlar parte vital de sua } \\
\text { demanda de exportação. Internamente os escravos se rebelavam e } \\
\text { uma crescente elite urbana pedia o fim da escravidão. }\end{array}$ \\
\hline 4 & $\begin{array}{l}\text { Qual foi a lei de } \\
\text { Bill Aberdeen? }\end{array}$ & Qualquer navio da marinha inglesa poderia deter navios negreiros. \\
\hline 5 & $\begin{array}{l}\text { Qual o nome e o ano da lei } \\
\text { que decretou o fim do tráfico } \\
\text { negreiro no Brasil? }\end{array}$ & Lei Eusébio de Queiroz, 1850. \\
\hline 6 & $\begin{array}{l}\text { Como a escravidão e a } \\
\text { economia se mantiveram no } \\
\text { Brasil durante os primeiros } \\
\text { anos após a aplicação dessa } \\
\text { lei? }\end{array}$ & $\begin{array}{l}\text { Muitos negros fugiam ou se rebelavam. Com o corte do } \\
\text { fornecimento externo, a escravidão estava em decadência. Cresceu } \\
\text { o tráfico interno de negros, principalmente do nordeste para o sul e } \\
\text { sudeste, já que o café era o grande produto de exportação da } \\
\text { época. } \quad \text { Economia } \quad \text { não } \quad \text { tão }\end{array}$ \\
\hline 7 & $\begin{array}{l}\text { Quais foram as medidas } \\
\text { tomadas no Brasil para } \\
\text { começar a se adequar } \\
\text { ao fim da escravidão e ao } \\
\text { inicio do trabalho livre? } \\
\text { (cite e explique ao menos } \\
\text { uma das medidas } \\
\text { mostradas no vídeo) }\end{array}$ & $\begin{array}{l}\text { Elevou-se o preço das terras para impedir que o camponês pudesse } \\
\text { comprar suas próprias terras obrigando-os a continuar trabalhando } \\
\text { nas fazendas. Com a mesma finalidade, os estrangeiros eram } \\
\text { impedidos de possuir terras e eram incorporados às fazendas. A lei } \\
\text { do Ventre Livre decretava que os filhos de escravos nascidos a } \\
\text { partir daquela data seriam livres. }\end{array}$ \\
\hline 8 & $\begin{array}{l}\text { Em que ano a escravidão } \\
\text { terminou de fato no Brasil? }\end{array}$ & 1888 \\
\hline
\end{tabular}

Fonte: Elaborado pelo autor com base na pesquisa realizada

\section{RESULTADOS}

Dos resultados coletados pelo experimento, foram geradas as tabelas I e II que criam uma relação entre o percentual de acertos para cada questão com o percentual de acertos de cada aluno individualmente, chegando assim à uma média geral, como podemos ver na última linha e coluna de ambas as tabelas.

Tabela I - Resultados Testes Grupo A. 


\begin{tabular}{cccccccccc}
\hline & Aluno & Aluno & Aluno & Aluno & Aluno & Aluno & Aluno & Aluno & Todos \\
os alunos
\end{tabular}

O, acerto Completo; X, Erro; P, acerto parcial.

Fonte: Elaborado pelo autor com base na pesquisa realizada

Tabela II - Resultados Testes Grupo B.

\begin{tabular}{cccccccc}
\hline & Aluno & Aluno & Aluno & Aluno & Aluno & Aluno & Todos \\
& 1 & 2 & 3 & 4 & 5 & 6 & os alunos \\
\hline Questão 1 & $\mathrm{X}$ & $\mathrm{O}$ & $\mathrm{X}$ & $\mathrm{X}$ & $\mathrm{X}$ & $\mathrm{O}$ & $33 \%$ \\
\hline Questão 2 & $\mathrm{X}$ & $\mathrm{X}$ & $\mathrm{X}$ & $\mathrm{X}$ & $\mathrm{X}$ & $\mathrm{P}$ & $08 \%$ \\
\hline Questão 3 & $\mathrm{O}$ & $\mathrm{X}$ & $\mathrm{X}$ & $\mathrm{O}$ & $\mathrm{X}$ & $\mathrm{O}$ & $50 \%$ \\
\hline Questão 4 & $\mathrm{X}$ & $\mathrm{O}$ & $\mathrm{X}$ & $\mathrm{X}$ & $\mathrm{O}$ & $\mathrm{O}$ & $50 \%$ \\
\hline Questão 5 & $\mathrm{P}$ & $\mathrm{P}$ & $\mathrm{P}$ & $\mathrm{O}$ & $\mathrm{P}$ & $\mathrm{O}$ & $66 \%$ \\
\hline Questão 6 & $\mathrm{X}$ & $\mathrm{X}$ & $\mathrm{X}$ & $\mathrm{X}$ & $\mathrm{P}$ & $\mathrm{O}$ & $22 \%$ \\
\hline Questão 7 & $\mathrm{O}$ & $\mathrm{O}$ & $\mathrm{O}$ & $\mathrm{O}$ & $\mathrm{P}$ & $\mathrm{O}$ & $91 \%$ \\
\hline Questão 8 & $\mathrm{X}$ & $\mathrm{X}$ & $\mathrm{X}$ & $\mathrm{X}$ & $\mathrm{O}$ & $\mathrm{X}$ & $17 \%$ \\
\hline Média geral & $31 \%$ & $43 \%$ & $19 \%$ & $37,5 \%$ & $43,5 \%$ & $82 \%$ & $43 \%$ \\
\hline
\end{tabular}

O, acerto Completo; $\mathrm{X}$, erro; $\mathrm{P}$, acerto parcial

Fonte: Elaborado pelo autor com base na pesquisa realizada

Pela observação das respostas do questionário, foi percebido que os alunos do grupo A, com vídeo não editado, acertaram $78,25 \%$ das perguntas gerais e $79,5 \%$ das perguntas específicas, enquanto os alunos do Grupo B, com vídeo editado, acertaram $49 \%$ das perguntas gerais e $35,25 \%$ das perguntas específicas. A média geral do grupo A foi de $78,8 \%$ de acerto, enquanto a do grupo B foi de $42,6 \%$.

Em relação às anotações: as tabelas III e IV foram desenvolvidas considerando todas as notas que se relacionavam com os assuntos reforçados pela tipografia da teleaula. Pôde ser notada, através delas, uma média similar de anotações principalmente nos tópicos mais abordados do vídeo como a lei Eusébio de Queiroz, a lei do ventre livre e a lei de terras. No entanto, em tópicos menos reforçados como a lei de Bill Aberdeen e principalmente em relação às datas, pôde ser notada uma redução relevante das anotações por parte do Grupo B.

Tabela III - Textos anotados do Grupo A. 


\begin{tabular}{lc}
\hline Textos anotados & $\begin{array}{c}\text { Quantidade de anotações } \\
\text { (de 8 alunos) }\end{array}$ \\
\hline 1850 & 7 \\
\hline Lei do ventre livre & 7 \\
\hline Lei Eusébio de Queiroz & 6 \\
\hline 1888 & 5 \\
\hline Tráfico interno de escravos & 4 \\
\hline Bill Aberdeen & 4 \\
\hline Lei de terras & 3 \\
\hline Liberalismo econômico & 2 \\
\hline 1845 & 2 \\
\hline Navio negreiro - & 2 \\
\hline Castro Alves & \\
\hline Fonte: Elaborado pelo autor com base na pesquisa realizada
\end{tabular}

Tabela IV - Textos anotados do Grupo B.

\begin{tabular}{lc}
\hline Textos anotados & $\begin{array}{c}\text { Quantidade de anotações } \\
\text { (de } 6 \text { alunos) }\end{array}$ \\
\hline Lei do ventre Livre & 5 \\
\hline Lei Eusébio de Queiroz & 4 \\
\hline Lei de Terras & 4 \\
\hline 1850 & 3 \\
\hline Bill Aberdeen & 1 \\
\hline
\end{tabular}

Fonte: Elaborado pelo autor com base na pesquisa realizada

\section{CONSIDERAÇÕES}

Através dos dados obtidos, pôde se constatar que o grupo de alunos que foi submetido ao vídeo com a LGV presente (Grupo A) acertou grande parte das questões do teste aplicado (com a média geral de acerto sendo de $78 \%$ ) e assimilou grande parte das informações específicas e detalhistas reforçadas pela LGV, como nomes e datas, que puderam ser constatados através da quantidade considerável de notas livres escritas pelos alunos.

Em contrapartida, o grupo de alunos que assistiu ao vídeo com a LGV removida (Grupo B) acertou um número consideravelmente menor das questões do teste aplicado (com média geral de acerto sendo de $43 \%$ ) e demonstrou ter dificuldade para assimilar as informações detalhistas e específicas menos abordadas dentro da vídeoaula, como pôde ser constatado através da menor quantidade de notas livres escritas pelos alunos.

Conclui-se então que, de acordo com as informações reforçadas pela LGV presente no vídeo, os alunos do Grupo A em relação com os do Grupo B possuíram em sua maioria uma atenção mais focada e direcionada ao que era relevante para a absorção do conteúdo abordado, evidenciando assim a importância dessa linguagem para o direcionamento de um conteúdo.

Mesmo com a baixa amostragem, os resultados desse experimento demonstraram fortes indícios que respondem ao questionamento inicial da pesquisa de maneira favorável: Através dele, pôde-se perceber que a linguagem gráfica verbal demostrou ter uma grande influencia para reforçar e direcionar conteúdos em mídias 
audiovisuais, com sua influência sendo facilmente notável ao pontuar as informações relevantes das vídeo-aulas.

Existiram, no entanto, fatores observados durante a realização do experimento que puderam ter influenciado nos resultados obtidos, tais como o conhecimento prévio do assunto por cada aluno, o interesse dos alunos por programas audiovisuais educativos assim como os diferentes níveis de dispersão e foco durante a exibição da vídeo-aula. Esses três fatores estavam presentes nos dois grupos, mesmo que em níveis diferentes, e uma das maneiras de anula-los seria realizar uma nova pesquisa com uma amostragem maior.

Ressalva-se que a presente pesquisa realizada foi apenas um pequeno experimento que, diante dos seus resultados positivos, nos aproximou de uma compreensão da necessidade e influencia da linguagem gráfica verbal sobre a linguagem falada nas mídias modernas. Esse experimento, no entanto, abre portas para diversas pesquisas relacionadas, começando pela confirmação dos seus resultados através de uma amostragem maior.

A ideia de experimentar a ausência de um elemento para compreender a sua influencia mostrou ser bastante diferenciada e passível de ser aplicada em diversos estudos futuros. Através dessa mesma abordagem em novos objetos de estudos, por exemplo, tanto poderemos mensurar o quanto a LGV pode auxiliar no direcionamento, foco e absorção de outros conteúdos específicos em disciplinas distintas como matemática ou geografia, quanto também poderemos explorar as diversas maneiras de se inserir a LGV durante a exibição de vídeos com conteúdos educativos.

Após uma melhor compreensão do papel da Linguagem Gráfica Verbal no direcionamento de conteúdos educativos, poderemos enfim definir diretrizes para a melhor inserção dessa linguagem na elaboração de novas vídeo-aulas, e com isso, contribuir para a transmissão de conteúdos dessa ampla mídia.

\section{REFERÊNCIAS}

BRISOLARA, Daniela Velleda. Linguagem gráfica verbal e tipografia do cotidiano. In: P\&D- Congresso Brasileiro de pesquisa e desenvolvimento em design, v.9, n.1. 2010.

CADENA, Renata Amorim; COUTINHO, Solange Galvão; ANDRADE. Bruna. A linguagem gráfica em artefatos educacionais gerados com ferramentas de TIC. In: InfoDesign Revista Brasileira de Design da informação, v.9, n.1. 2012.

DERRIDA Jacques. Primeiros passos: da linguagem à escritura. em: Revista Mente, Cérebro \& Filosofia, São Paulo, v. 12. 2008.

LUPTON, Ellen e MILLER, Abbott. Design Writing Research: writing on graphic design. Londres: Phaidon. 1999.

SCHOLLES, Luís. Ambiente virtual para aprendizagem. Brasil, 2008. Disponível em: < http://estudodeead.blogspot.com.br/2008/09/artigo-sobre-ead.html>. Acesso em 19 mar. 2014

SCHRIVER, Karen A. Dynamics in document design, USA, 1997, Jonh Wiley \& Sons, ISBN 0-471-30636-3. 
TELECURSO. Metodologia telessala. Fundação Roberto Marinho, Brasil, 2011. Disponível em: < http://www.telecurso.org.br/metodologia-telessala/>. Acesso em 19 mar. 2014

TELECURSO. O que é. Fundação Roberto Marinho, Brasil, 2008. Disponível em: < http://www.telecurso.org.br/o-que-e/>. Acesso em 19 mar. 2014

TWYMAN, Michael. The graphic presentation of language. Information Design Journal, vol 3(1), 1982, Grillford Ltd. Stony Stratford, Milton Keynes, UK 2-22.

VIEIRA, Alexandre. Educação à distância: perspectivas para uma aprendizagem autônoma em ambientes colaborativos. Brasil, 2013. Disponível em: < http://www.fflch.usp.br/dlcv/lport/pdf/slp01/13.pdf>. Acesso em 19 mar. 2014

WOLLMAN, Matt - Type in Motion 2. New York, Thames \& Hudson, 2005 